\title{
VIDA E MORTE DO GRANDE SISTEMA ESCOLAR AMERICANO: COMO OS TESTES PADRONIZADOS E O MODELO DE MERCADO AMEAÇAM A EDUCAÇÃO*
}

\author{
SARA BADRA DE OLIVEIRA ${ }^{* *}$ \\ Rita de CÁssia Silva GodoI MenEGão**
}

$\mathrm{E}$

m seu livro Vida e morte do grande sistema escolar americano, Diane Ravitch expõe de forma acessível e detalhada a evolução das reformas de mercado no sistema escolar dos Estados Unidos nas últimas décadas, criticando seus pressupostos ideológicos e denunciando seus resultados, que contribuíram para agravar a crise da educação pública americana.

Como acadêmica e propositora de políticas inserida no aparelho de Estado, a autora analisa as reformas que ela antes endossara com entusiasmo, e que agora passa a criticar diante das evidências de seus resultados. Ravitch é pesquisadora-doutora da Universidade de Nova Iorque. Em 1991, ela aceitou o convite do então secretário Lamar Alexander para ser sua conselheira e secretária-adjunta no Departamento de Educação dos Estados Unidos. Também esteve envolvida como conselheira nos governos Bill Clinton e George W. Bush e participou ativamente de movimentos pelas referências curriculares, responsabilização e escolha escolar.

A primeira edição do livro lançada no Brasil contém agradecimentos da autora, apresentação escrita por José Clovis de Azevedo e mais onze capítulos seguidos das notas com bibliografia e do índice. No primeiro capítulo, "O que eu aprendi sobre a reforma escolar", Ravitch analisa sua trajetória profissional, os cargos políticos exercidos, os trabalhos acadêmicos desenvolvidos e as soluções outrora defendidas, e como ela foi retirando seu apoio das populares soluções baseadas na lógica do mercado.

\footnotetext{
* Resenha do livro de autoria de Diane Ravitch, traduzido por Marcelo Duarte (Porto Alegre: Sulina, 2011).

* Mestranda do Laboratório de Observação e Estudos Descritivos (Loed), da Faculdade de Educação da Universidade Estadual de Campinas (Unicamp). E-mail: sarabadra@hotmail.com

*** Doutoranda do Loed, da Faculdade de Educação da Unicamp. E-mail: ritamenegao@gmail.com
} 
No segundo capítulo, "Sequestrado! Como o movimento pelas referências curriculares se transformou no movimento de testagem", ela expõe como a responsabilização baseada em teste tornou-se o principal motor da reforma escolar, substituindo o movimento pelas referências curriculares. Em "A transformação do Distrito 2", é descrita a experiência desse distrito, que foi eleito símbolo nacional de como ampliar a escala da reforma, tornando-se uma fórmula a ser transposta para outros sistemas. Os capítulos seguintes, "Lições de San Diego" e "A lógica de mercado em Nova Iorque", descrevem detalhadamente as experiências que foram influenciadas pelo Distrito 2, explicitando o caráter empresarial das reformas de responsabilização e das políticas organizacionais aplicadas no distrito de San Diego e na cidade de Nova Iorque.

O capítulo seis, "NCLB: testar e punir", expõe as características e determinações principais da lei federal que selou a era da responsabilização baseada em dados, assumindo um papel de interferência nas escolas locais como nunca antes na história do federalismo americano. Em "Escolha escolar: a história de uma ideia" fica claro que, desde 1980, a questão da "escolha"1 escolar povoa a arena de discussões e propostas para a educação, materializando-se sobretudo nos vouchers e nas populares escolas administradas por concessão. ${ }^{2}$ No capítulo oito, “O problema com a responsabilização", Ravitch condensa as críticas, sempre sinalizadas ao longo do livro, às reformas de mercado, mostrando um conjunto de pesquisas e evidências contrárias à responsabilização baseada em teste.

Em “O que a Sra. Ratliff faria?”, a autora recorre à lembrança de sua antiga e inspiradora professora para expor como a lógica da atual reforma desvaloriza o que ela considera ser um bom professor e passa a girar em torno de uma noção específica de "professor eficiente", explicando como isso afeta nas políticas de gerenciamento dessa força de trabalho. O capítulo dez, "O clube dos bilionários", explica o funcionamento da poderosa rede de filantropia privada que apoia a reforma, conferindo-lhe enorme fôlego e limitando o alcance das vozes e movimentos de resistência.

Por fim, no último capítulo, "Lições aprendidas", Ravitch exalta sua posição de defensora da escola pública, conclui que as atuais reformas colocam a educação pública em perigo e sinaliza o que ela acredita que seja uma educação de qualidade e o caminho que se deve percorrer para alcançá-la, deixando claro que não existem "panacéias" ou fórmulas mágicas quando se trata de educação.

A autora adota uma postura sincera e corajosa ao rever suas posições e admitir que as soluções de mercado não estão alcançando as melhorias esperadas no desempenho dos alunos. Os EUA permanecem estagnados em avaliações nacionais (Naep) e internacionais (Pisa). ${ }^{3}$ Para além dos números, a crítica mais fundamental de Ravitch é que essas soluções de mercado estão erodindo os valores públicos e a própria educação pública, que ela advoga como uma instituição essencial para 
a democracia e para a constituição de uma nação economicamente forte e repleta de oportunidades.

Ela manteve sua posição em defesa da escola pública e das referências curriculares. Permanece endossando que o sistema educacional defina claramente seus objetivos, através de um currículo rico e coerente que englobe uma formação abrangente, além das habilidades básicas, que têm sido o alvo restrito dos testes atuais. No início do livro, ela analisa como as novas reformas se distanciaram dessa preocupação fundamental com o currículo e passaram a acreditar que mudanças na gestão e na estrutura do sistema seriam prontamente a solução para os problemas da educação. Os princípios empresariais de gestão e contratação de profissionais, escolha, recompensas e punições para incentivar a força de trabalho, decisões e metas baseadas em um bom sistema de dados, passam a ser soluções por si mesmas, negligenciando as dimensões pedagógica e política da educação.

A questão da reforma escolar tem sido politicamente popular nos Estados Unidos desde os anos de 1980. Em 1983, o relatório A Nation at Risk (Anar) ${ }^{4}$ foi emblemático, pois mostrou em tom direto e incendiário o fracasso do sistema educacional em cumprir seu papel como instituição acadêmica a serviço do desenvolvimento do país. Ao sinalizar a necessidade urgente de mudança, o Anar influenciou o início do movimento pela reforma baseada em referências curriculares. No entanto, devido às controvérsias acaloradas que surgiram em torno do currículo nacional de história, esse movimento ruiu em 1994, sendo substituído por esforços de reforma cujo foco não era mais o que os estudantes deveriam aprender.

O foco das atuais reformas restringe-se à responsabilização baseada em teste, ignorando preocupações essenciais sobre qual educação se espera e como fazer para melhorar as escolas públicas que enfrentam dificuldades. Ao invés de lidar com esses problemas espinhosos, parece mais fácil entregar a administração das escolas à iniciativa privada, sob o argumento de que ela fará melhor do que a administração pública engessada e ineficaz. A criação das escolas administradas por concessão, iniciada nos anos de 1990, representa especialmente essa crença.

Além dessa forma de privatização, os princípios empresariais são injetados no aparelho do Estado, que passa a utilizar um sistema de dados - os testes de múltipla escolha de habilidades básicas dos estudantes - como base para decisões de responsabilização, que envolvem recompensas e punições para escolas e seus profissionais, conforme atinjam as metas de desempenho. A elevação das pontuações dos testes passa a ser o objetivo educacional, representando a medida da eficiência de professores e escolas.

Esquivando-se da questão da produção da desigualdade na sociedade, os reformadores acreditam que professores eficientes sejam capazes de resolver o problema da disparidade de desempenho entre estudantes de diferentes grupos sociais. 
Equipes constantes de professores eficientes poderiam ser formadas se os administradores pudessem demitir à vontade os ineficientes e vincular o pagamento aos escores dos estudantes. Porém, à medida que o profissional é julgado com base em resultados mensuráveis, sua experiência e qualificações são desvalorizadas. Para alcançar esses objetivos, tenta-se eliminar os sindicatos e a estabilidade do professor, considerados uma barreira à gestão eficaz dos recursos humanos e das condições de trabalho.

A infusão de ideias de mercado na educação pública é acompanhada pela injeção de grandes somas de dinheiro por poderosos empresários e suas grandes fundações, que assumem para si a tarefa de reformar a educação. Assim, a reforma abre suas portas para o domínio de profissionais de diversas áreas, sobretudo do meio empresarial, contribuindo para a desvalorização da profissão docente.

As fundações financiam desde organizações que terceirizam professores ${ }^{5}$ até escolas públicas, empresas de escolas por concessão, treinamento de diretores de escolas e superintendentes distritais, programas públicos e movimentos políticos que defendam seus interesses de mercado, formando uma rede de filantropia privada que passa a definir a agenda política da reforma educacional dos governos. A filantropia da virada do milênio não arrisca deixar o planejamento das reformas para seus beneficiários; são as próprias fundações que definem o que e como realizar, e quais organizações são apropriadas para suas doações, cobrando um retorno de seu investimento através de medidas concretas de efetividade.

As principais fundações dos EUA - Gates, Walton e Broad - representam juntas uma força além do alcance das instituições democráticas. Por serem organizações privadas, não estão sujeitas à supervisão e revisão do público, o que condena a educação ao capricho dos financiadores e empreendedores e ao sabor da instabilidade do mercado. A definição da agenda de reforma é ideologicamente dominada por esses atores, que desqualificam qualquer posição contrária como avessa à mudança e defensora do engessado status quo.

Ravitch expõe as experiências emblemáticas de dois distritos que capturaram a atenção dos reformadores de mercado, o Distrito 2, da cidade de Nova Iorque, e San Diego. Ansiosos por encontrar um programa de reforma que pudesse alcançar escores de testes mais altos, os reformadores ficaram animados com a estratégia implementada em finais de 1980 no Distrito 2, crentes de que haviam encontrado um molde pronto para ser facilmente imposto por líderes firmes com intuito de atingir resultados rápidos. A reforma do Distrito 2 influenciou posteriormente a reforma de San Diego, em 1998, e da cidade de Nova Iorque, em 2001.

A verticalidade dessas reformas chamava a atenção. O superintendente de San Diego acreditava que mudanças eficazes são impostas rapidamente a partir de um centro gestor, e concentrou-se em demitir professores e diretores que não 
cumpriam prontamente as ordens centrais, demandar maiores escores nos testes, atacar a burocracia, lutar contra o sindicato dos professores e abrir escolas por concessão.

Em Nova Iorque, o prefeito e seu secretário de Educação foram mais ousados, conseguindo obter em 2002 o controle direto sobre as escolas da cidade. Empenharam-se em promover a "escolha" escolar, através do estímulo às escolas por concessão e às pequenas escolas de ensino médio, e programas de responsabilização envolvendo incentivos e sanções. Em 2007, o Departamento de Educação de Nova Iorque adotou um programa de pagamento por mérito, que oferecia bônus às escolas que atingissem progressos anuais em seus escores de testes. ${ }^{6}$

Ravitch critica a política verticalizada dessas reformas, que desconsideram a complexidade do processo educacional, cujas mudanças ocorrem de forma incremental, conforme os atores locais se apropriem de significados compartilhados e desenvolvam relações de confiança (cf. Bryk et al., 2010) em suas comunidades profissionais. Além disso, o controle direto sobre as escolas elimina os mecanismos de revisão pública de decisões, necessários em uma democracia para garantir a legitimidade e credibilidade das decisões políticas.

Em 2002, o governo Bush teve força suficiente para aprovar uma nova legislação federal para a educação, a lei No Child Left Behind (NCLB), ${ }^{7}$ graças ao apoio bipartidário que girava em torno da necessidade de maior responsabilização para as escolas. Essa lei selou a era da responsabilização baseada em dados, que exacerbou a importância dos testes, tornando-os fins em si mesmos. O destino de profissionais e escolas passou a ser decidido com base na pontuação dos estudantes nos testes de habilidades básicas de leitura e matemática.

A lei deixava os estados americanos livres para administrarem seus próprios testes e definirem seus próprios níveis de proficiência. A meta era que todas as escolas e distritos realizassem progressos anuais para cada grupo de estudantes em direção ao objetivo de $100 \%$ de proficiência até 2014 . As escolas que fracassassem em alcançar o progresso estariam sujeitas a vários graus de sanções, entre os quais seus profissionais poderiam ser demitidos, a escola poderia ser fechada ou (eufemisticamente) "reestruturada", convertendo-se em escola por concessão. Não há uma estratégia de orientação e apoio para as escolas que necessitem de melhoria. Pressupõe-se que as ameaças de demissão dos profissionais e de fechamento das escolas sejam suficientes para incentivá-los a melhorar. Caso não sejam, acredita-se que a administração privada será mais eficaz em alcançar bons resultados para os estudantes necessitados.

Exigir metas inatingíveis, combinadas à ausência de estratégias de assistência, contribui para aumentar cada vez mais o número de escolas públicas que se encontram em risco de serem fechadas ou transformadas em escolas por concessão, 
o que representa uma contagem regressiva para a demolição da educação pública. A reforma gera sutilmente um círculo vicioso, à medida que sua programação abala a confiança nas instituições públicas e na profissão docente, embasando mais demanda para privatizar a administração das escolas, assim como para desprofissionalizar a educação.

Os reformadores acreditam que as escolas por concessão, livres da regulamentação estatal, sejam capazes de alcançar melhores resultados e injetar dinamismo e competição no sistema, contribuindo para estimular a melhoria das escolas públicas regulares. Deixar a administração das escolas aberta ao grande fluxo de iniciativas privadas produziria uma saudável variedade no sistema educativo, proporcionando escolha às famílias dos estudantes que não conseguissem progredir nas escolas regulares. Desregulamentação, competição e escolha pareciam soluções óbvias.

O apelo para a criação de escolas administradas por concessão já era forte na década anterior à NCLB, fazendo parte de legislações estaduais e da legislação federal do governo Clinton, e permanece forte no governo Obama, apesar da ausência de evidências que comprovem a superioridade do setor como um todo. As pesquisas não mostram um padrão que permita afirmar que as escolas por concessão sejam melhores em alcançar bons resultados para os estudantes. Só é possível afirmar que a variedade na qualidade dessas escolas é enorme, incluindo desde aquelas excelentes a escolas precárias controladas por pessoas corruptas e incompetentes.

No entanto, não surpreende a insistência dos políticos em adotar esse modelo para a reforma, pois o entusiasmo pelas soluções de mercado e a posição ideológica contrária ao setor público superaram a busca por evidências empíricas. Ravitch sinaliza que o verdadeiro debate sobre as escolas por concessão é ideológico e não será esgotado com a incansável guerra de dados.

Assim como certas escolas públicas regulares, algumas administradas por concessão registram altos escores nos testes padronizados. Esses dados são suficientes para animar os reformadores e a mídia a projetarem uma imagem de sucesso para essas escolas como um todo. No entanto, estudos mostram que, por trás desses dados, existem certas condições que favorecem as escolas administradas por concessão. Elas atraem os estudantes mais motivados, podem dispensar aqueles de baixo desempenho ou que não cumpram seu código disciplinar, além de receberem recursos financeiros adicionais de grandes fundações, o que lhes permite oferecer turmas menores e mais tempo para atividades.

Ao contrário do que previram os defensores da escolha, as escolas públicas não estão melhorando com a competição. Elas acabam recebendo os estudantes de baixo desempenho e fraca motivação, sinalizando uma tendência de queda contínua em seus escores. A privatização das escolas tende a criar um sistema de dois níveis 
cada vez mais desigual, sem contribuir para encarar o desafio que permanece em aberto, de como educar todos os estudantes.

Ravitch expõe dados do Naep que mostram resultados desanimadores nos anos após a implementação da NCLB. Mais fundamental que isso, ela critica os pressupostos errôneos de como melhorar as escolas e sinaliza as distorções provocadas por eles. Na era da responsabilização, os testes extrapolaram sua função diagnóstica e adquiriram uma dimensão preocupante com propósitos de grandes consequências, sob a crença de que são uma ferramenta infalível capaz de identificar quais profissionais devem ser demitidos ou recompensados e quais escolas devem ser fechadas.

No entanto, por mais bem construídos que sejam, os testes são sempre imprecisos e sujeitos a variações aleatórias, erros humanos ou problemas técnicos. São limitados para medir o conhecimento dos estudantes, e ainda mais limitados para medir a qualidade das escolas e de seus profissionais. Eles podem fornecer importantes informações sobre o progresso das escolas, mas não devem ser utilizados como o único dado a partir do qual decisões importantes são tomadas.

Os testes assumem o poder de responsabilizar as escolas como se seus resultados refletissem apenas o que nelas ocorre e o que seus profissionais fazem para educar os estudantes. Sabe-se, no entanto, que são múltiplos os fatores que afetam o desempenho nos testes. A responsabilização focada nas escolas ignora a parte de responsabilidade dos estudantes e suas famílias, e do poder público em prover condições adequadas de trabalho. Os professores não são responsáveis sozinhos pelo aprendizado dos estudantes, e nem tudo de valor que um professor transmite aos seus alunos pode ser apreendido em um teste padronizado.

Quando as pessoas são pressionadas a satisfazerem medidas limitadas de desempenho, suas ações irão concentrar-se obsessivamente nos aspectos que influenciam estas medidas, negligenciando os outros objetivos da educação e os aspectos qualitativos do trabalho que não podem ser mensurados. A pressão por aumentar os escores dos testes de habilidades básicas pode produzir escores maiores e, ao mesmo tempo, uma educação pior. Professores concentram-se em ensinar aquilo que conta para os esquemas de responsabilização, prestando menos atenção às outras disciplinas e dimensões da formação, além de restringir o ensino a atividades de treinamento para testes (cf., também, Hout \& Elliott, 2011; Madaus et al., 2009).

É bem conhecida a ocorrência de truques e atalhos para atingir os resultados desejados, como a manipulação da população testada, ou a diminuição dos níveis de exigência nos testes estaduais. Outra distorção é que os estudantes mais necessitados recebem menos atenção, pois os professores concentram seus esforços nos alunos próximos da média, que demonstrem maiores chances de progredir em curto prazo e elevar a média de desempenho (cf. Neal \& Schanzenbach, 2010). Além disso, 
as escolas passam a competir pelos melhores estudantes e a adotar mecanismos velados de exclusão dos alunos que ameacem reduzir os escores da escola.

Ravitch defende um sistema de responsabilização que avalie as escolas com objetivo de ajudá-las a melhorar. O sistema de avaliação de professores e alunos deveria ser mais amplo que medidas de desempenho em testes padronizados, além de incluir outros atores, como o poder público, igualmente responsáveis pela capacidade das escolas em prover um bom ensino.

Fechar escolas não resolve o problema e ainda contribui para destruir instituições estabelecidas e fragmentar laços de comunidade. A escolha das famílias é que sua escola de bairro seja bem-sucedida; é obrigação do sistema público que todas as escolas o sejam, assim como é obrigação dos gestores buscar soluções reais para as escolas públicas que enfrentam dificuldades.

Decisões importantes de demissão e recompensa não podem ser feitas de forma leviana, baseadas em dados limitados. Demissões são possíveis e necessárias quando se trata de servidores negligentes e descompromissados com a moral do serviço público. Contudo, o julgamento profissional não deve basear-se apenas nos escores dos testes; deve incluir avaliações conduzidas por educadores experientes e formas de assistência da equipe escolar a professores com dificuldade. Os dados são importantes, mas isoladamente não oferecem uma justa medida do trabalho do professor e não podem substituir a avaliação em campo por um profissional experiente na área educacional.

Ravitch defende o fortalecimento da profissão docente, por meio do reconhecimento da importância da experiência e da formação inicial, enraizada na disciplina lecionada e na pedagogia. Além disso, a profissionalização deve incluir um apoio constante em serviço de mentores e colegas.

Ela reforça que os ricos objetivos da educação não sejam reduzidos a pontuações em testes, os quais devem ser apenas um indicador. Quando o teste torna-se objetivo principal vinculado a fortes consequências, ele próprio é invalidado e perdem-se de vista os objetivos essenciais da educação. Ravitch defende a importância de um currículo enraizado nas artes e ciências, que incite os estudantes à busca pelo conhecimento, desenvolva sua cidadania, capacite-os a refletir criticamente sobre questões e a tomar decisões sensatas sobre a própria vida, e contribua para formação do caráter e disciplina.

Para ela, as mudanças organizacionais propostas não irão resolver os problemas da educação, pois o sucesso das escolas depende de múltiplos fatores, como a definição de um currículo sólido, professores bem preparados, materiais, recursos e condições adequadas de trabalho, estudantes dispostos, pais apoiadores, e outros serviços ligados a uma reforma social mais ampla. 
Também fica claro que a lógica de mercado não é apropriada para prover educação pública. A competição por clientes, o atendimento ao público de forma diferenciada e a oscilação de oferta fazem parte da esfera do mercado, mas perdem o sentido quando são transpostas para a esfera pública, encarregada de prover direitos sociais que devem ser garantidos a todos, independente do poder político e da posição na esfera produtiva. As esferas pública e privada podem coexistir, mas possuem objetivos de natureza distinta e devem ser regidas de acordo com a lógica coerente com seus objetivos.

Ravitch terminou de escrever o livro em 2009 e a publicação da primeira edição saiu em 2010. Porém, desde o seu lançamento, novas pesquisas e eventos significativos ocorreram na educação americana, fomentando na autora a necessidade de escrever um epílogo, intitulado School and Society ("Escola e Sociedade"), que por enquanto foi acrescentado somente na segunda edição do livro em inglês, lançada em 2011.

Desde o lançamento da primeira edição, surgiram importantes movimentos de resistência de vários grupos organizados, incluindo atores como pais e professores; escândalos emergiram apontando fraudes praticadas em grandes sistemas (como Nova Iorque), antes exaltados pelos reformadores devido aos seus "excelentes resultados"; e importantes pesquisas continuam a demonstrar a incapacidade das políticas de mercado em prover melhor educação para os estudantes, bem como as distorções provocadas por elas.

No entanto, a ebulição desses acontecimentos e de tantas evidências contrárias não foi suficiente para abafar o movimento de reforma empresarial, que adquiriu novo fôlego graças aos investimentos contínuos do setor filantrópico privado, às publicações acaloradas da mídia - como a do jornal Newsweek, sem contar o glamour agora conquistado em Hollywood com o lançamento do documentário Esperando pelo super-homem, em 2010.

Essas narrativas transbordam na exposição de dados para demonstrar o fracasso do sistema escolar público, atribuído à incompetência dos professores e à proteção dos sindicatos. O documentário defende, por meio de recursos dramáticos, que a única solução para as crianças ${ }^{8}$ é abrir mais escolas por concessão e poder demitir professores à vontade. No entanto, assim como a história do Newsweek, esse documentário baseia-se em meias-verdades, dados distorcidos, exageros e interpretações equivocadas.

Ravitch expõe as diversas falhas dos argumentos expostos nessas narrativas, que tipicamente desconsideram a implicação que a desigualdade social exerce no aprendizado dos estudantes. A pobreza, ela reforça, é um fato, não uma "desculpa" como alegam os reformadores. Ela também denuncia que expor o sindicato como 
"contrário aos interesses das crianças" é um apelo injusto dos reformadores, ansiosos por reduzir investimento público e privatizar escolas públicas sem enfrentar oposição organizada.

A reforma adquiriu o apoio crucial do presidente Obama e seu secretário de Educação Arne Duncan, com o lançamento do programa federal "Corrida para o topo" ${ }^{\prime \prime} \mathrm{em} 2009$, segundo o qual seriam elegíveis para competir pelos fundos federais somente os estados que concordassem em adotar as prescrições do programa. Basicamente, o "Corrida para o topo" estimula a criação de escolas administradas por concessão - ousando ainda mais, prevendo eliminação dos limites para sua criação nos estados - e o uso das estratégias punitivas da NCLB nas escolas de baixo desempenho. Porém, esse programa foi mais longe que a lei, acrescentando que os estados aspirantes ao fundo deveriam concordar em demitir e recompensar os professores com base nas pontuações dos testes dos estudantes.

A publicação deste livro é bem vinda no Brasil, pois permite que façamos uma análise crítica das reformas educacionais em nosso país, tanto nos estados e municípios como na esfera federal.

Em São Paulo, por exemplo, a reforma educacional vem sendo conduzida de acordo com os mesmos pressupostos de mercado. Empresários, grandes empresas e fundações se mobilizam em movimentos e associações, como "Todos pela Educação" e "Parceiros da Educação", com objetivo de "melhorar o aproveitamento escolar dos alunos", influenciando e contribuindo com as políticas públicas de educação através de ações de parceria junto à Secretaria de Educação do Estado de São Paulo e às escolas (envolvendo desde formação continuada de professores/coordenadores, reforço escolar, à elaboração de plano de ação da política educacional e das escolas), além de ações de mobilização em torno de suas diretrizes e de divulgação dos resultados das metas por eles estabelecidas.

O interesse deles é compreensível, uma vez que a educação adquire caráter de urgência e prioridade para o desenvolvimento do novo modo de produção capitalista (cf. Freitas, 1991). A parceria público-privado também se manifesta na forma de arranjo de desenvolvimento da educação (ADE), um regime de colaboração recém-homologado pelo Ministério da Educação, que prevê a coparticipação de estados, municípios e instituições privadas e não governamentais na "melhoria da educação".

Abriu-se um mercado para a indústria das consultorias, que recebem a responsabilidade de definir projetos de governos - a exemplo do projeto implementado no estado de São Paulo ${ }^{10}$ e outros (cf. Brooke, 2011) -, elaborar os testes de larga escala e, atualmente, realizar pesquisas encomendadas, financiadas pelos cofres públicos e grupos de executivos e fundações. ${ }^{11}$ 
Proliferam projetos e programas que contribuem para a desvalorização e precarização da profissão docente. Estes introduzem nas escolas - por meio dos próprios sistemas públicos, organizações e parcerias entre ambos - "monitores", "oficineiros", "tutores", "trainees", ou seja, profissionais sem experiência/qualificação docente, contratados temporariamente para atuar com os alunos em atividades culturais, esportivas, artísticas, e de reforço escolar, especialmente em escolas de vulnerabilidade social, ${ }^{12}$ caracterizando a natureza marginal desses programas. Por trás disso, nota-se a desresponsabilização do Estado em prover professores bem formados na área e em melhorar as condições de trabalho da categoria docente.

O exaltado discurso "professor é tudo"13 não é de valoração, mas de responsabilização, e de acordo com ele a culpa pela defasagem de aprendizagem dos alunos é da ineficiência do professor. Ao invés de se moverem pela lógica da profissionalização docente, os reformadores desvalorizam a formação inicial e defendem que salário e progresso na carreira sejam baseados na produtividade dos professores, medida pelo desempenho de seus alunos nos testes padronizados.

Assim, as reformas empresariais corrompem o "espírito do serviço público" ao atrelar pagamento a variações aleatórias do mercado como nível de produtividade, ao invés de vinculá-lo ao verdadeiro valor do trabalho e aos valores do servidor, como tempo de serviço e qualificação. ${ }^{14}$ Nesse cenário, valoriza-se a formação em exercício, em sua maioria por meio da $\mathrm{EaD}$, na qual as aulas presenciais são substituídas por um plantão tira-dúvidas com tutores do programa.

Os testes padronizados de habilidades básicas já são bem conhecidos no Brasil em todos os níveis - municipal, estadual e federal ${ }^{15}$ - e alguns servem como base para premiar professores nas redes que implementaram programas de pagamento de bônus. ${ }^{16}$ Alguns desses programas baseiam-se em outras medidas como taxas de evasão escolar, e até mesmo o que chamam de "avaliação institucional" - que seriam questionários online respondidos pelo corpo profissional e discente sobre vários aspectos de sua escola. ${ }^{17}$

Vale ressaltar que vários estudos (cf. Hout \& Elliott, 2011; Madaus et al., 2009; Neal \& Schanzenbach, 2010) já demonstraram a ocorrência de distorções - como avaliações inflacionadas - quando o objetivo da avaliação restringe-se à responsabilização sob a forma de punição e recompensa. Estudo de Marsh et al. (2011) sobre uma das experiências mais consolidadas de implementação de programa de bônus (o caso de Nova Iorque) já demonstrou que o bônus não foi um fator de motivação capaz de gerar mudança nas práticas dos professores e no desempenho dos estudantes, e que a maioria dos professores é motivada por fatores intrínsecos relacionados ao seu desenvolvimento profissional e à aprendizagem dos alunos. 
Também já presenciamos no Brasil acalorados discursos em favor da publicização dos dados e exposição dos resultados do Ideb na porta das escolas, como estratégia de pressão para gerar constrangimentos aos "mal classificados" e proporcionar escolha aos estudantes vistos como clientes. Vale mencionar também que algumas instituições públicas aderiram ao contrato de trabalho, ${ }^{18}$ sob a crença de que o mecanismo de gerenciamento dos recursos humanos do setor privado é mais eficaz que o estatutário com estabilidade. Essa crença desconsidera as características peculiares do serviço público, que preveem uma relação própria com o dinheiro, o tempo e o poder (cf. Supiot, 1995), baseadas no compromisso do servidor com o atendimento ao público.

No Brasil, pressupostos semelhantes aos criticados por Diane Ravitch vêm conduzindo as mudanças em vários sistemas educacionais locais e têm influenciado as propostas de gestores públicos e a opinião da população, atraindo-os às promessas de uma solução rápida para os problemas da educação. A mídia permanece contribuindo incansavelmente para a construção do pensamento hegemônico de que a escola "privada é boa e a pública ruim", deixando o terreno fértil para a introdução dessas mudanças que creditam à lógica privada a solução óbvia para a ineficácia da educação, apesar da ausência de evidências que comprovem o sucesso dessas políticas nos Estados Unidos.

Os defensores da escola pública devem estar cientes de que a disputa não se encerrará pela apresentação de dados desfavoráveis; mas aponta, sobretudo, para questões sobre que democracia queremos, sobre qual educação se espera construir e para qual tipo de sociedade. Por resgatar o percurso da educação americana, esse livro torna-se leitura indispensável para todos que pretendam compreender e discutir os atuais rumos das políticas educacionais brasileiras.

\section{Notas}

1. Modalidade de privatização que incentiva os pais a escolherem a escola de seu filho através de vouchers (ou cheque educação).

2. Na tradução brasileira, o tradutor Marcelo Duarte traduz charter school como "escola autônoma". No entanto, optamos por utilizar "escolas administradas por concessão", pois as escolas charter são escolas públicas operadas privadamente por concessão. São escolas públicas de gestão privada.

3. Naep - Avaliação Nacional do Progresso na Educação, feita pelo Departamento de Educação americano. Pisa - Programa Internacional de Avaliação de Alunos, feito pela OCDE.

4. Uma Nação em Risco.

5. A exemplo da Teach for America (TFA), uma organização que recruta universitários inexperientes, recém-formados em qualquer área, para lecionar por dois anos em escolas públicas que acolhem estudantes de baixa renda, após receberem um breve treinamento de cinco semanas.

6. O estudo de Marsh et. al. (2010) demonstrou que o programa de bônus de Nova Iorque não foi capaz de gerar mudanças significativas no desempenho dos alunos e nas práticas docentes.

7. No Child Left Behind. 
8. O documentário acompanha a trajetória de cinco crianças ávidas por escaparem de suas escolas públicas e conquistarem uma vaga em escolas charter, administradas por concessão, mostradas no filme como excelentes. Vale notar que são crianças motivadas, de famílias pobres, porém estruturadas e que valorizam a escola e os estudos.

9. O documentário Race to nowhere ("Corrida para lugar nenhum"), lançado em 2010, faz uma referência irônica a esse programa, representando o lado das vozes contrárias à atual abordagem de reforma.

10. A exemplo da política de bônus para os profissionais da educação do estado de São Paulo, normatizada em 2009.

11. Cesgranrio, CNI, FGV-RJ, FGV-SP, Fundação Itaú Social, Fundação Santillana, Fundação SM, Fundação Victor Civita, IBGE, Ibmec-SP/Insper, Ibope, Inep, Instituto Paulo Montenegro e Instituto Unibanco são exemplos de organizações com as quais são feitas parcerias para realização de estudos e pesquisas, que visam trazer conhecimentos sobre a realidade educacional brasileira.

12. A exemplo da Teach for America (TFA), que chegou ao Brasil (ver matéria veiculada pelo jornal $O$ Globo em 18/07/2010, disponível em: <http://oglobo.globo.com/rio/escolas-municipais-terao-reforcode-trainees-2977626> (acesso em: 27 fev. 2012).

13. Como exemplo do vídeo do movimento "Todos pela Educação", disponível em: <http://www.youtube. com/watch?v=wVKQ8yMV-14> (acesso em: 16 abr. 2012).

14. Supiot (1995) define o "espírito do serviço público" como um tipo próprio de moral profissional que inclui relações com o poder, o dinheiro e o tempo essencialmente diferentes das relações da lógica do setor privado. Reivindicações de salário baseadas em critérios de tempo e formação seriam compatíveis com a defesa do "espírito do serviço público", pois são critérios que reafirmam valores inerentes à pessoa do servidor, e não o valor de mercado da prestação de serviço.

15. A exemplo da Prova São Paulo (municipal), Saresp (estadual) e Prova Brasil (federal).

16. Brooke (2011) sinaliza alguns estados como Pernambuco, São Paulo e Espírito Santo, nos quais o pagamento de bônus foi implementado.

17. A exemplo do Centro Estadual de Educação Tecnológica Paula Souza (vinculado à Secretaria de Tecnologia de São Paulo), que provê formação de nível técnico e superior, além de ensino médio.

18. A exemplo do Centro Paula Souza, que realiza contrato via CLT.

\section{Referências}

BROOKE, N. As novas políticas de incentivo salarial para professores: uma avaliação. In: FONTOURA, H.A. (Org.). Políticas públicas, movimentos sociais: desafios à pós-graduação em Educação em suas múltiplas dimensões. Rio de Janeiro: ANPEd Nacional, 2011. p. 163-188.

BRYK, A.S. et. al. Organizing schools for improvement: lessons from Chicago. Chicago: University of Chicago, 2010.

FREITAS, L.C. Formação do professor para o amanhã: transformação ou modernização. Cadernos do CED, Florianópolis, n. 17, p. 5-17, 1991.

HOUT, M.; ELLIOTT, S.W. (Ed.). Incentives and test-based accountability in education. Washington, DC: The National Academies, 2011. 
MADAUS, G. et al. The paradoxes of high-stakes testing: how they affect students, their parents, teachers, principals, schools, and society. Charlotte: Information Age, 2009. MARSH, J.A. et al. A Big Apple for educators: New York city's experiment with schoolwide performance bonuses. Santa Monica: Rand Corporation, 2011.

NEAL, D.; SCHANZENBACH, D.W. Left behind by design: proficiency counts and test-based accountability. Review of Economics and Statistics, Cambridge, Mass., v. 92, n. 2, p. 263-83, 2010. Disponível em <http://www.mitpressjournals.org/doi/abs/10.1162/ rest.2010.12318>. Acesso em: 24 fev. 2012.

RAVITCH, D. The death and life of the great American school system: how testing and choice are undermining education. Rev. ed. New York: Basic Books, 2011.

RAVITCH, D. Vida e morte do grande sistema escolar americano: como os testes padronizados e o modelo de mercado ameaçam a educação. Trad. de Marcelo Duarte. Porto Alegre: Sulina, 2011.

SUPIOT, A. A crise do espírito de serviço público. Adverso, Porto Alegre, v. 5, n. 7, p. 17-25, 1995.

\section{Sites}

PARCEIROS da Educação. Disponível em: <www.parceirosdaeducacao.org.br> TODOS pela Educação. Disponível em: <www.todospelaeducacao.org.br> 